\title{
Pump Damage in the Hanshin Earthquake*
}

\author{
TOSHIYUKI OSADA \\ Pump Section, No. 1 Environmental Systems Department, Mitsubishi Heavy Industries, Ltd., \\ 5-1, Marunouchi 2-Chome, Chiyoda-ku, Tokyo, Japan
}

(Received 30 June 1998; In final form 3 November 1998)

\begin{abstract}
There was a severe earthquake in the southern area of Hyogo prefecture in Japan on January 17,1995 . In this paper the damage to pump facilities caused by the earthquake, based on field investigation results in the Hanshin (Osaka-Kobe) area is reported. In particular a lot of damage was reported in the pumping facilities for sewage or drainage of storm sewage. This paper also presents recommendations for aseismic design of pump facilities based on the results of the survey.

Some of the kinds of damage to pumps were: pump submersion, shaft misalignment, case of pump rotor getting stuck, anchor bolt failure, pump casing cracking, bearing box failure. Most of the damage was fundamentally caused by unequal sinking of the building foundation. The damage to the pumps was mainly caused by deformation or collapse of building structures, or by excessive forces to be exerted on the pumps by the piping.

In order to prevent damage to pumps by earthquakes, a study of the earthquake resistance of the whole pumping facility including the pump itself should be made, and appropriate countermeasures and action taken.
\end{abstract}

Keywords: Turbopumps, Aseismic design, Damage and failure of pumps by earthquake, Submersion, Misalignment, Crack

\section{INTRODUCTION}

An earthquake of magnitude 7.2 (on the Richter scale) occurred in the southern area of Hyogo prefecture in Japan at 5:46 a.m. on January 17, 1995. The earthquake killed more than 6000 people in the densely populated Hanshin area (OsakaKobe). At the same time there was a lot of damage to machinery facilities in this area, which is one of the representative industrial areas in Japan. Damage to lifeline facilities due to other great earthquakes were examined and reported so far by Anton (1981) and Lund (1994). As an example of one of the few great earthquakes which have occurred in modern cities, examination of damage to the machinery facilities of lifeline and study of measures for preventing recurrence of such damage are extremely important for stable supply of electricity, gas and water as well as improvement of reliability of various industrial plants.

* This paper was originally presented at ISROMAC-7.

${ }^{\dagger}$ Tel.: 81332129622 . Fax: 81332129847. E-mail: Q19044@hq.mhi.co.jp. 
It is important also to ensure proper functioning of pump facilities so that the associated infrastructure remains operational. It is difficult at present to provide a law for aseismic standards for all devices, machinery, piping, etc. Some pumps have been designed based on manufacturers' experience or standards. So it is meaningful to make detailed examinations and studies on the damage caused by the earthquake to pumps.

In this paper the damage to the pump facilities caused by the earthquake is reported based on field investigation results in the Hanshin (Osaka-Kobe) area. In particular a lot of damage was found in the pumping facilities for sewage or drainage of storm sewage. This paper also presents recommendations for aseismic design of pump facilities based on the results of the survey.

\section{RESULTS OF DAMAGE EXAMINATION}

\subsection{Method of Damage Examination}

The damage to the pump facilities examined and presented by the Association for Pump System Engineering and by nine pump manufacturers is evaluated and summarized in this paper. The following shows the scope of the present examination.

(a) Area subjected to examination: the whole Hanshin area.

(b) Pump facilities subjected to examination:

(1) waterworks, sewage and drainage of storm sewage which are public facilities;

(2) various manufacturing facilities such as thermal power plants, iron works, chemical plants, machinery works and food plants;

(3) general machinery facilities such as building air-conditioning systems and water supply equipment.

Total number of the pump facilities in the above is estimated to be huge if we include small-size facilities (especially the facilities in (3)). Therefore it is extremely difficult to enumerate the total number of pump facilities regardless of presence or absence of damage; only the damaged pump facilities were examined. It is not expected that this examination can cover all damage, but the damage to the main pump facilities in the Hanshin area is covered. However, since number of the damaged private facilities is not as clear as public ones, comparison between them is not meaningful.

\subsection{Outline of Types of Damage}

Table I shows the classification of the damaged pump facilities based on application. In total sixty damaged pump facilities were reported but it was found that there were many damaged sewage systems and storm sewage drainage systems among them. Mainly medium and large pumps of 300$1700 \mathrm{~mm}$ in discharge opening diameter were installed in these facilities. On the other hand no damage was found in thermal power plants and iron works where many large and small pumps are installed.

In total 90 cases of damage were found in these sixty facilities. Cases of damage were counted in such a way that when the same type of damage occurred in the same facility where more than one pump was installed in a pump facility the damage was counted as one case.

Table II shows the result sorted according to number of cases, assumed cause, measure and disposal, type of pump, discharge opening diameter (representative size reflecting size of pump), etc. and the damage phenomenon. The total number of damage cases reported is 90 . Since multiple cases of damage of the same content occurred in the

TABLE I Application and number of damaged pump facilities (there were many damaged sewage systems and storm sewage drainage systems)

\begin{tabular}{llc}
\hline & \multicolumn{1}{c}{ Application of facilities } & Number of facilities \\
\hline 1 & Sewage system & 26 \\
2 & Drainage of storm sewage & 21 \\
3 & Water works & 9 \\
4 & Chemical plants & 2 \\
5 & Food plant & 1 \\
6 & Building air-conditioning system & 1 \\
& Total & 60 \\
\hline
\end{tabular}




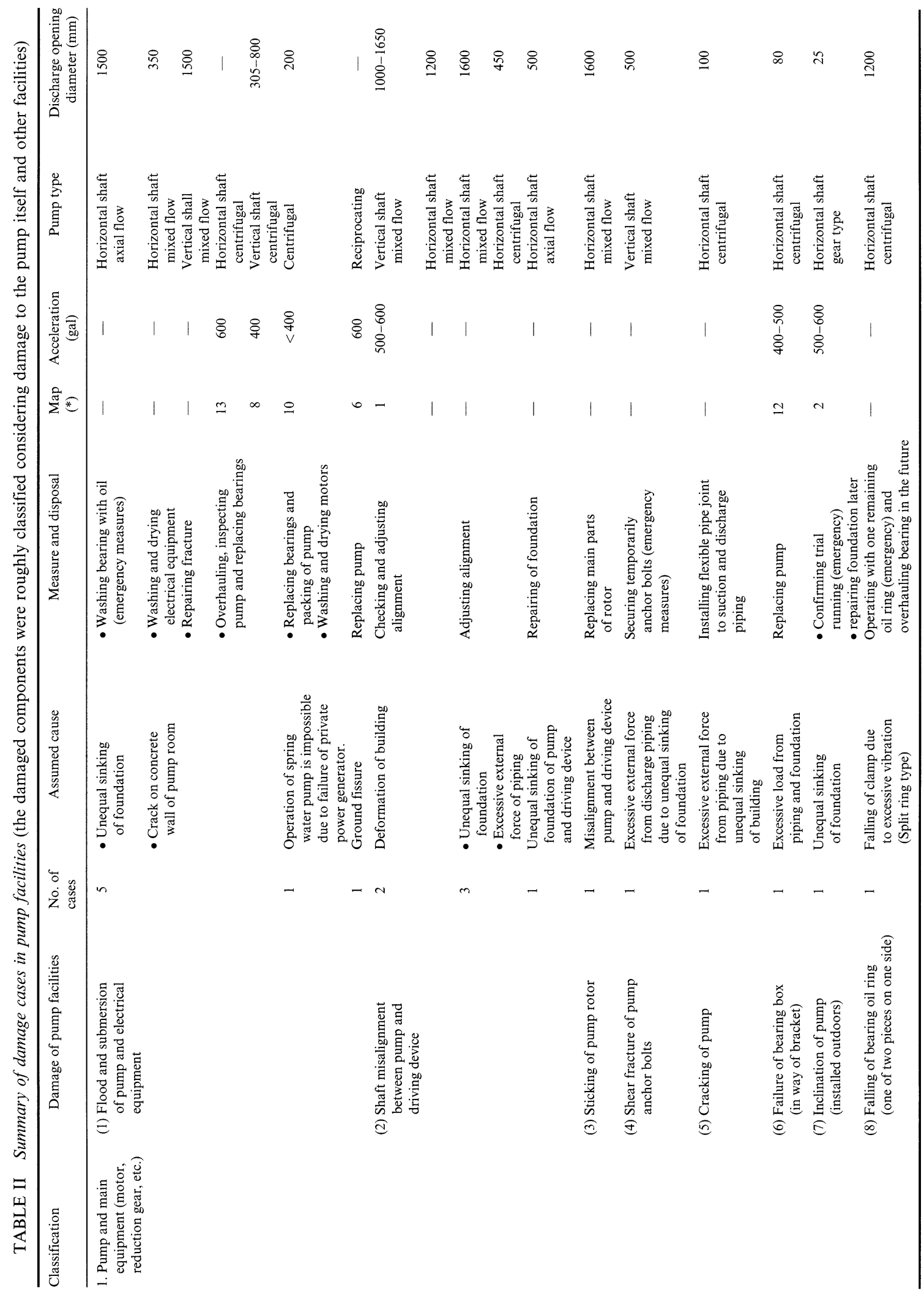




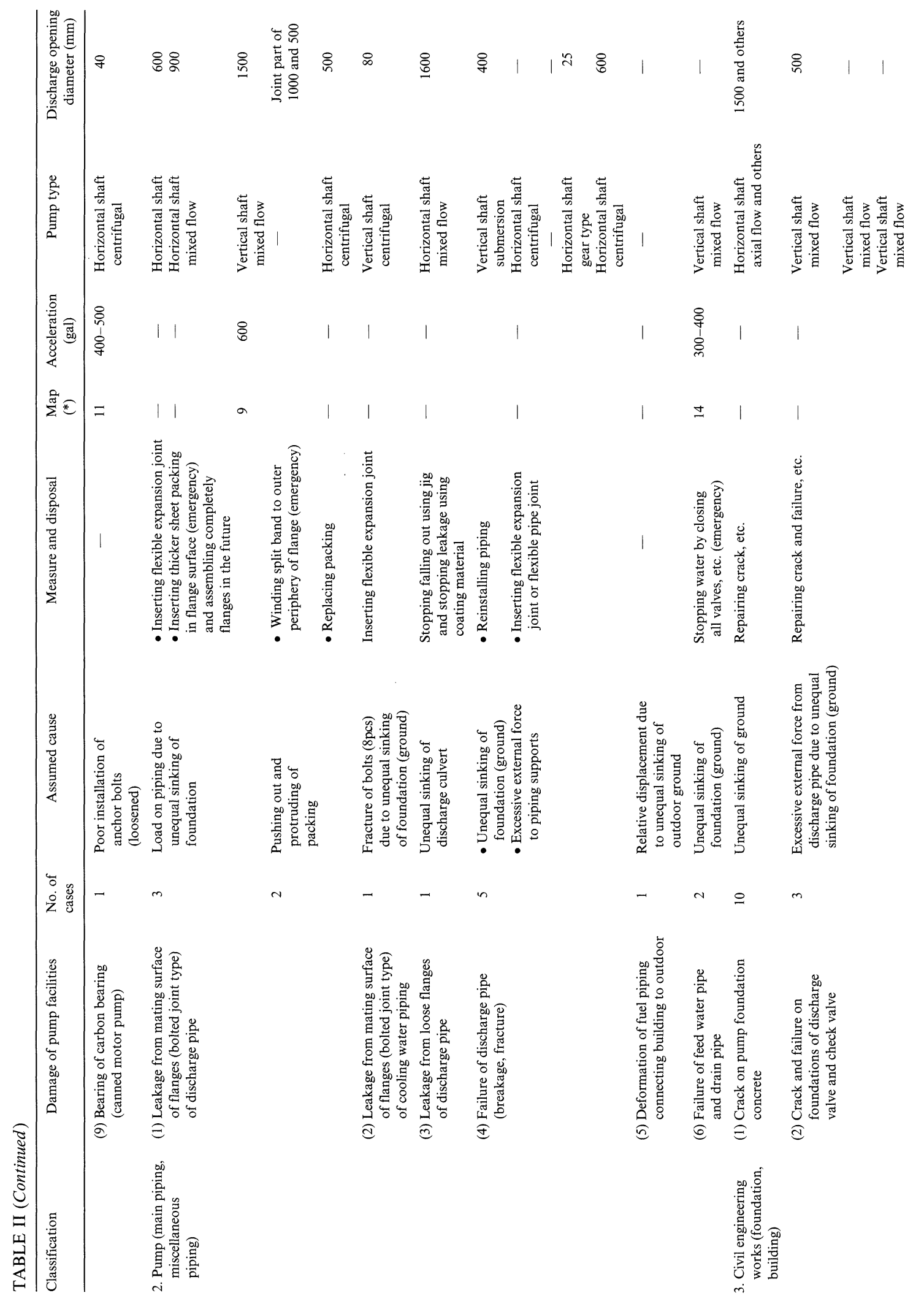


喜裏

In

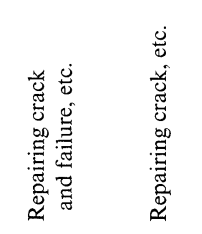

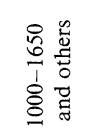

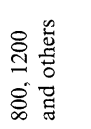

\&.

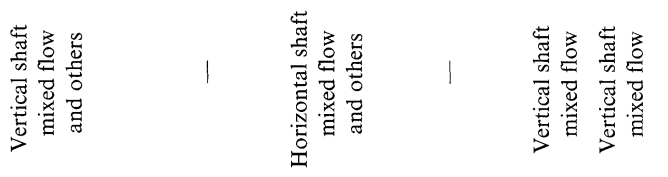

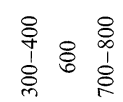

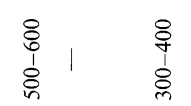

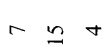

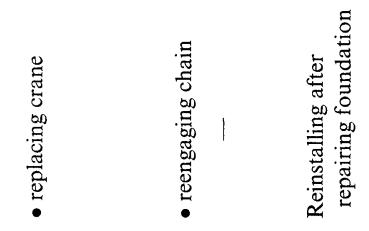

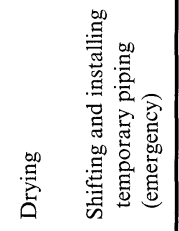

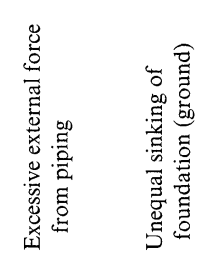

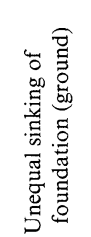

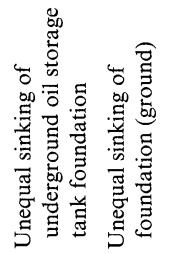

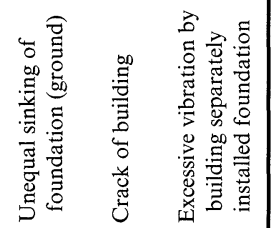

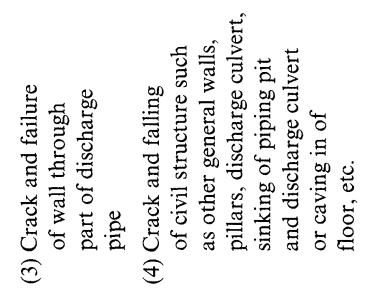
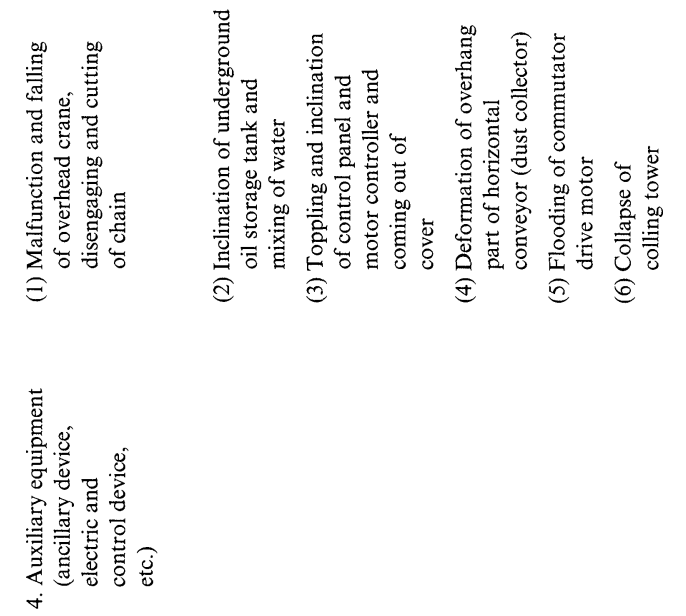
different pump facilities, these cases were rearranged as the same phenomenon. The damaged components were roughly classified as follows considering damage to the pump itself and other facilities.

Classification of damaged facility components:

(1) pump and main equipment (motor, reduction gear, etc.);

(2) piping (main piping, miscellaneous piping);

(3) civil engineering works (foundation, building);

(4) auxiliary equipment (ancillary device, electric and control device, etc.).

Figure 1 shows the ratio of each of damaged facility components in the above to total number of damage cases in the pump facilities. The number of cases of damage to pumps is small and the ratio is $22 \%$. It is found that most cases occurred in the civil engineering works rather than the pumps themselves.

Details of the damage in each facility are described in the following:

(a) Pump As shown in Fig. 2, the types of damage on pumps were mostly flood and submersion of pump and shaft misalignment which corresponds to $65 \%$ of the total number of damage. Other types of damage on pumps were

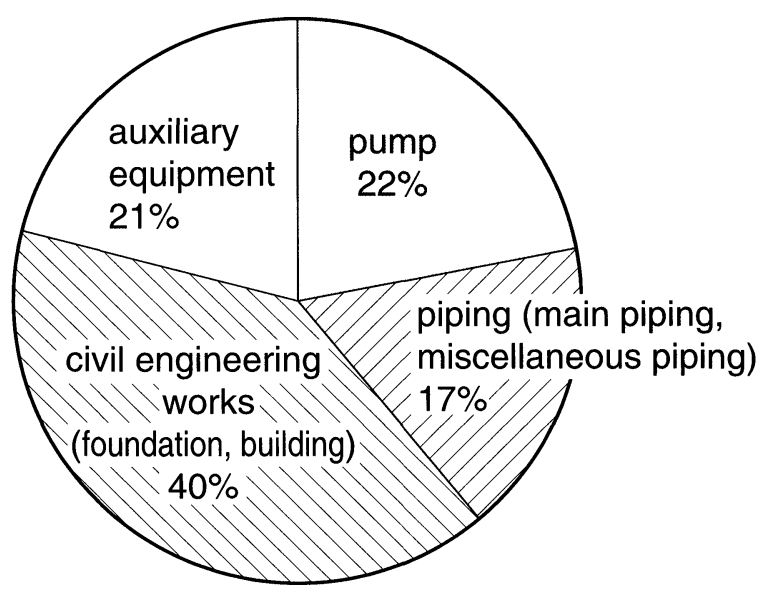

FIGURE 1 Details of damage to pump facilities. The number of cases of damage to pumps were small, and most cases occurred in the civil engineering works.

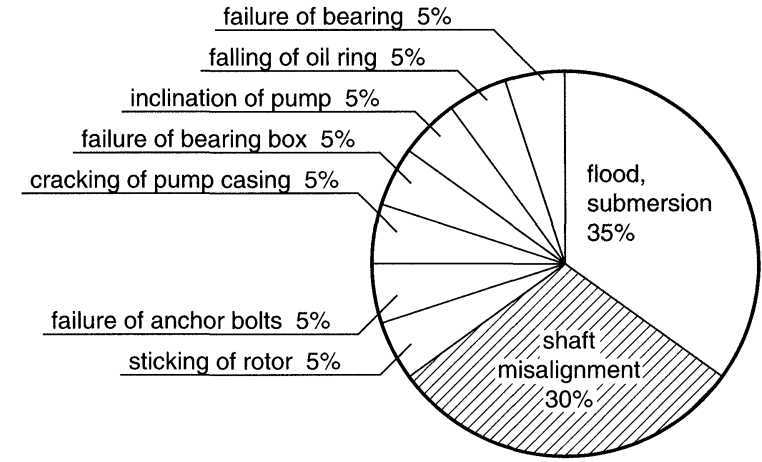

FIGURE 2 Details of damage to pumps. The types of damage on pumps were mostly flood and submersion of pump and shaft misalignment.

\section{deformation of piping $7 \%$}

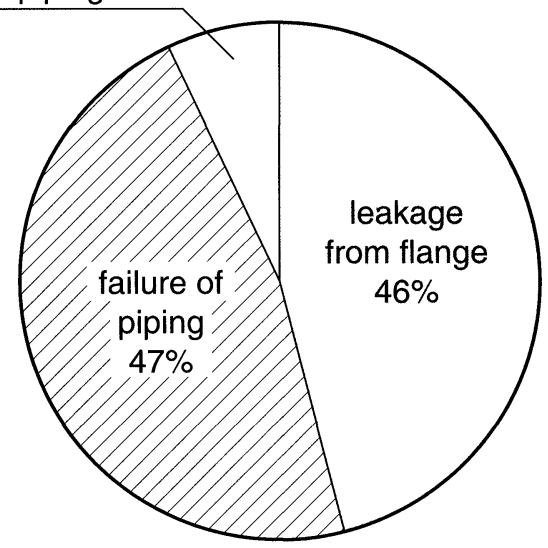

FIGURE 3 Details of damage to piping. The types of damage to the piping were roughly classified into leakage from flange mating surface and failure of piping.

sticking of pump rotor, failure of anchor bolts, cracking of pump casing, failure of bearing box, etc. with only one case for each type of damage.

(b) Piping As shown in Fig. 3, types of damage to the piping are roughly classified into leakage from flange mating surface and failure of piping. The number of these types corresponds to $93 \%$ of the total types of damage.

Most of the flanges that failed are of rigid type coupled to each other with bolts.

(c) Civil engineering works Damage to the civil engineering works as shown in Fig. 4 is due to crack or failure of the pump foundation 


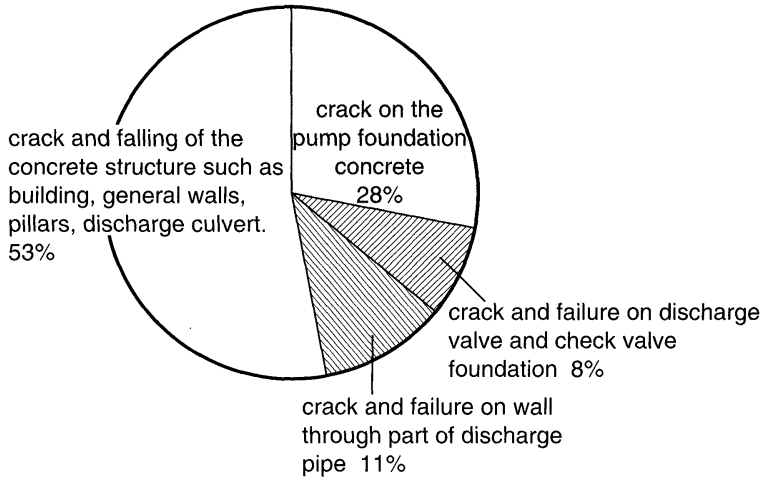

FIGURE 4 Details of damage to concrete structures. The types of damage to concrete structures were crack or failure of the pump foundation concrete, wall through part of discharge pipe, and foundations of discharge valves and check valves.

concrete, wall through part of discharge pipe, and foundations of discharge valves and check valves, which are important installation parts for mechanical equipment. These types of damage correspond to $47 \%$ of the total.

(d) Auxiliary equipment As representative cases, falling and failure of overhead cranes, inclination of an underground oil storage tank and turning-over of a control panel are reported.

\subsection{Examples of the Pump Damage}

Causes of types of damage on pumps are presented below:

(a) Flooding and submersion of pump and electrical equipment Figure 5 shows the layout of a horizontal shaft mixed flow pump (discharge opening diameter $350 \mathrm{~mm}$ ). Cracks occurred on the concrete walls of the tank and the underground pump room; the pump room was flooded and the pumps and electric equipment were damaged. The flood water went into the bearings, damaging the bearings. Cracking was caused by the dissimilar local displacements of adjacent buildings. As emergency measures, the bearings were washed with oil and the electrical equipment were dried. For preventing recurrence of damage,

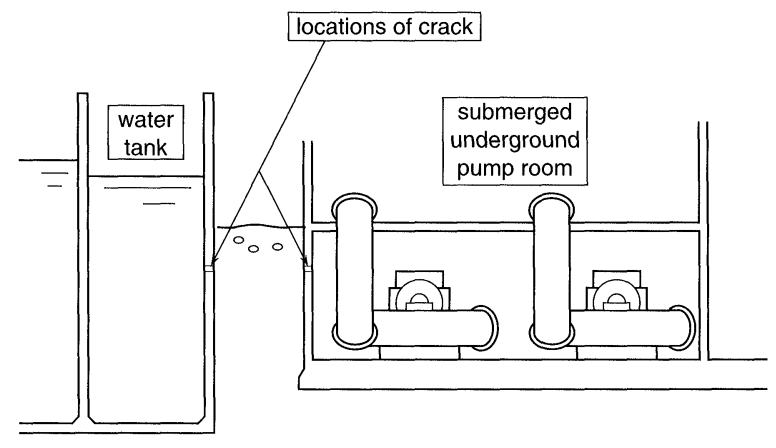

FIGURE 5 Pump submersion. The pump room was flooded due to cracks on the concrete walls of the tank and the underground pump room.

it is necessary to integrate the foundation structure and to strengthen the foundation.

(b) Shaft misalignment between pump and driving machine Figure 6 shows a damaged vertical shaft mixed flow pump (discharge opening diameter $1650 \mathrm{~mm}$ ). The pump and the reduction gear are installed on separate foundations (two-floor type). The axial thrust of the pump shaft is supported by the reduction gear, and the pump and the reduction gear are coupled with a rigid type coupling.

During the inspection of the pump, after the earthquake, it was found that the alignment between the pump shaft and reduction gear shaft deviated in the radial direction, and the deviation exceeded the allowable value for installation and adjustment of the pump and the reduction gear. The cause of misalignment is considered to be slight distortion of the building due to two-floor type foundation. Other abnormalities could not be found, therefore the alignment was readjusted.

To maintain functions of the pump facilities even after earthquakes, adoption of a flexible shaft coupling (laminated sheet type coupling, gear coupling, universal joint, etc.) is recommended so that a larger misalignment can be allowed for. However in this case the axial thrust bearing should be integrated in the pump, resulting in complicated pump design.

(c) Pump rotor getting stuck Figure 7 shows the installation of a horizontal shaft mixed flow 


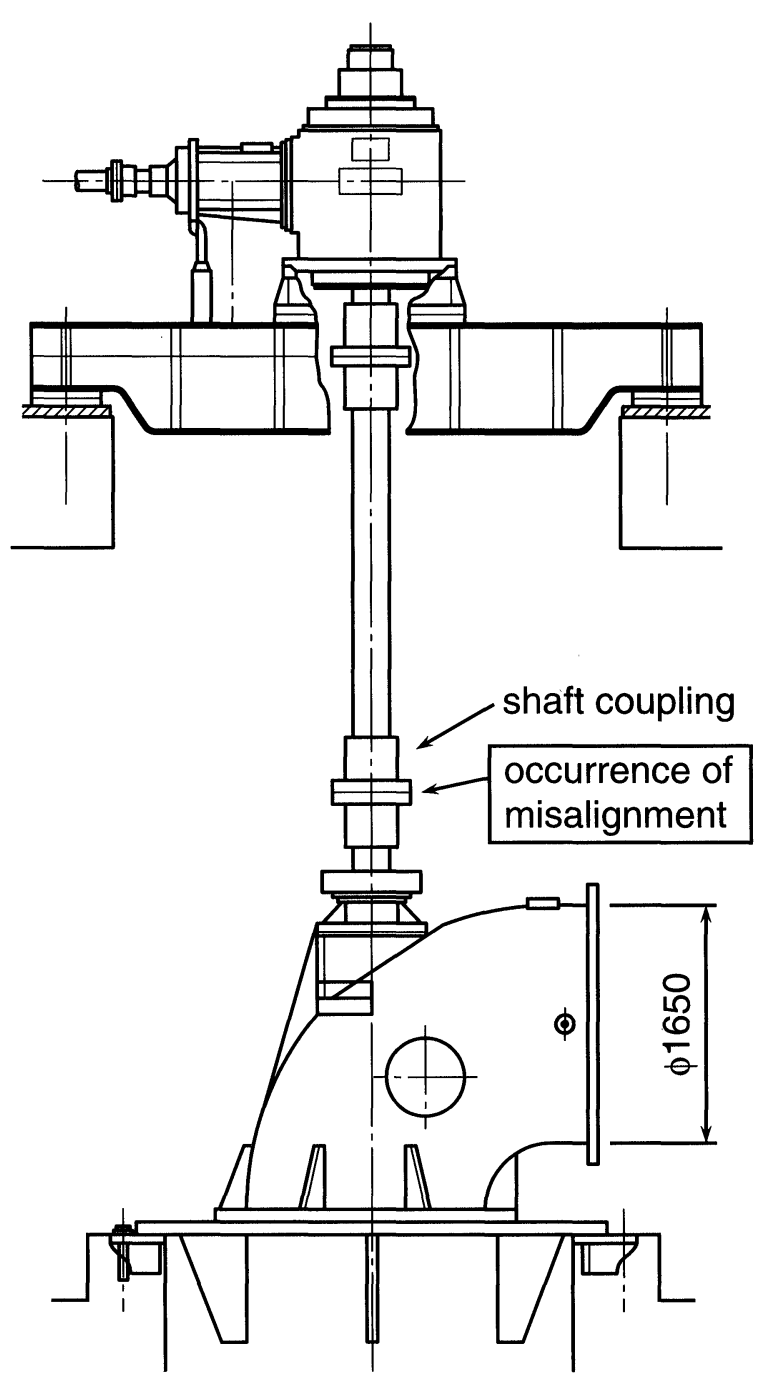

FIGURE 6 Shaft misalignment. The alignment between the pump shaft and reduction gear shaft deviated in the radial direction because of slight distortion of the building.

pump (discharge opening diameter $1600 \mathrm{~mm}$ ). Since excessive external force was applied to the pump due to unequal sinking of delivery culvert, misalignment occurred, resulting in sticking of the pump rotor. In addition there was leakage from the loose flange. To repair the damage, the main parts of the pump rotor were replaced. The leakage from the flange part was stopped by loose stop using jig and by coating, before the pump was reassembled. To prevent recurrence, installa- tion of a flexible expansion joint to the piping where foundation strength changes rapidly, adoption of a flexible shaft coupling to the pump and integration of the structure foundations should be considered.

(d) Anchor bolt failure Figure 8 shows installation of the vertical shaft mixed flow pump (discharge opening diameter $500 \mathrm{~mm}$ ). Since a large load from the piping due to unequal sinking of foundation and inertia force in earthquake was applied to the pump, shear fracture of all the pump anchor bolts $(\mathrm{W} 1 \times 4)$ and failure of the motor-operated valve foundation occurred. Photo 1 shows failure of the anchor bolts. The anchor bolts were temporarily fixed as an emergency measure. Thereafter they were completely restored. In order to reduce inertia force and absorb relative displacement of devices owing to unequal sinking of the foundation generated by earthquake, study of installation of a flexible expansion joint to the piping is required.

(e) Suction casing cracking Figure 9 shows a plan view of the installation of a horizontal shaft centrifugal type pump (discharge opening diameter $100 \mathrm{~mm}$ ). It is assumed that the inlet pipe and pump casing were pulled apart by excessive piping external force due to unequal sinking of the building, and failure of the pump casing occurred. Failure occurred adjacent to the inlet flange of the pump casing. As correction measures, the casing was replaced and flexible pipe joints were fitted to the suction and discharge pipings.

(f) Bearing box failure Earth and sand were blown in due to fluidization phenomenon in over a half of the plant area, and rising, fall and cracking of the ground occurred in many places in the vicinity of the wharf of Kobe port. Cracks of the pump foundation occurred and also, as shown in Fig. 10, several horizontal shaft centrifugal type pumps (discharge opening diameter $80 \mathrm{~mm}$ ) sustained damage such as complete failure in the bracket part of the pump bearing box. The cause of the damage is assumed to be excessive load from the piping and foundation. As a 


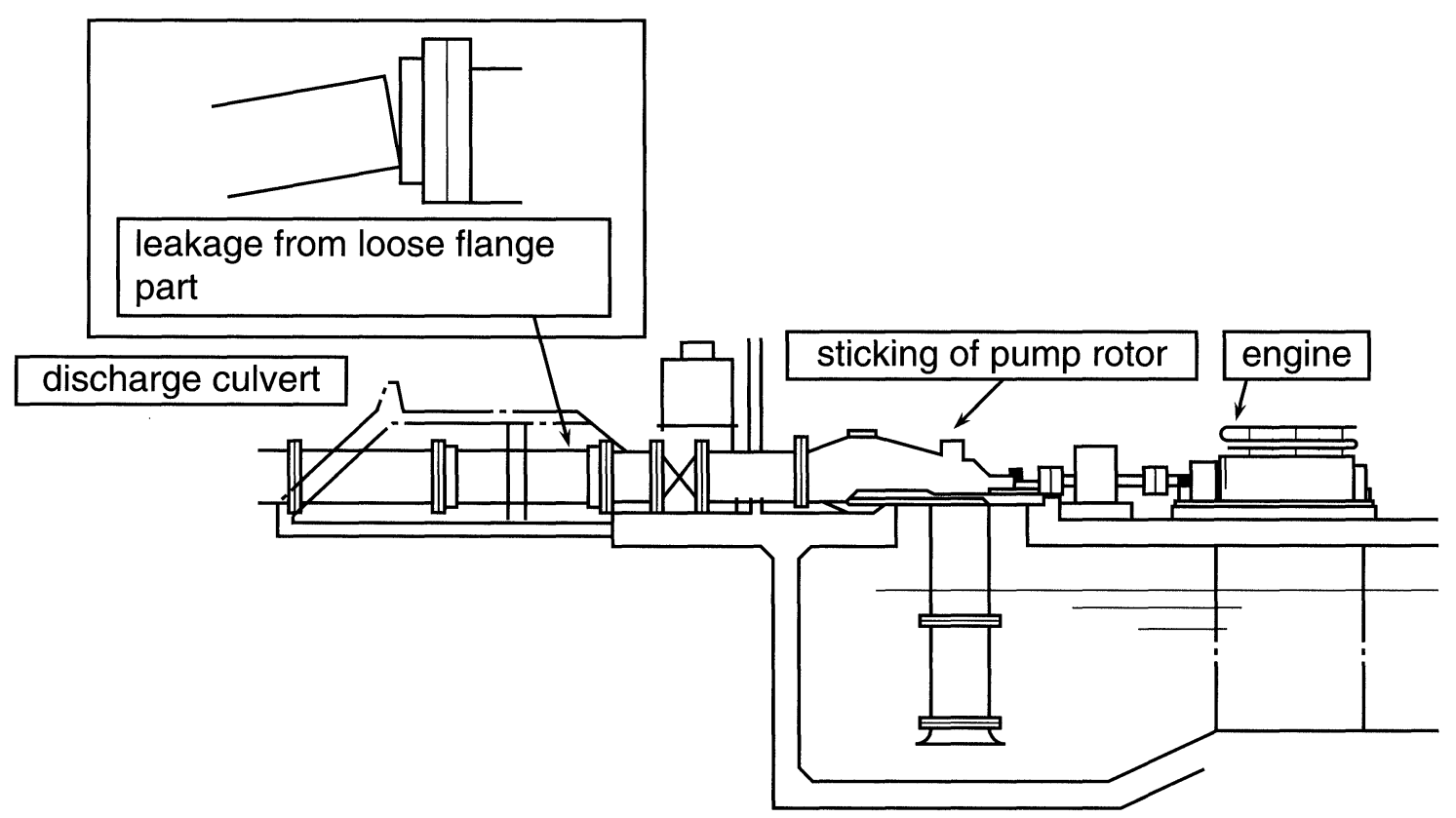

FIGURE 7 Pump rotor getting stuck. Since excessive external force was applied to the pump due to unequal sinking of delivery culvert, misalignment occurred, resulting in sticking of the pump rotor.

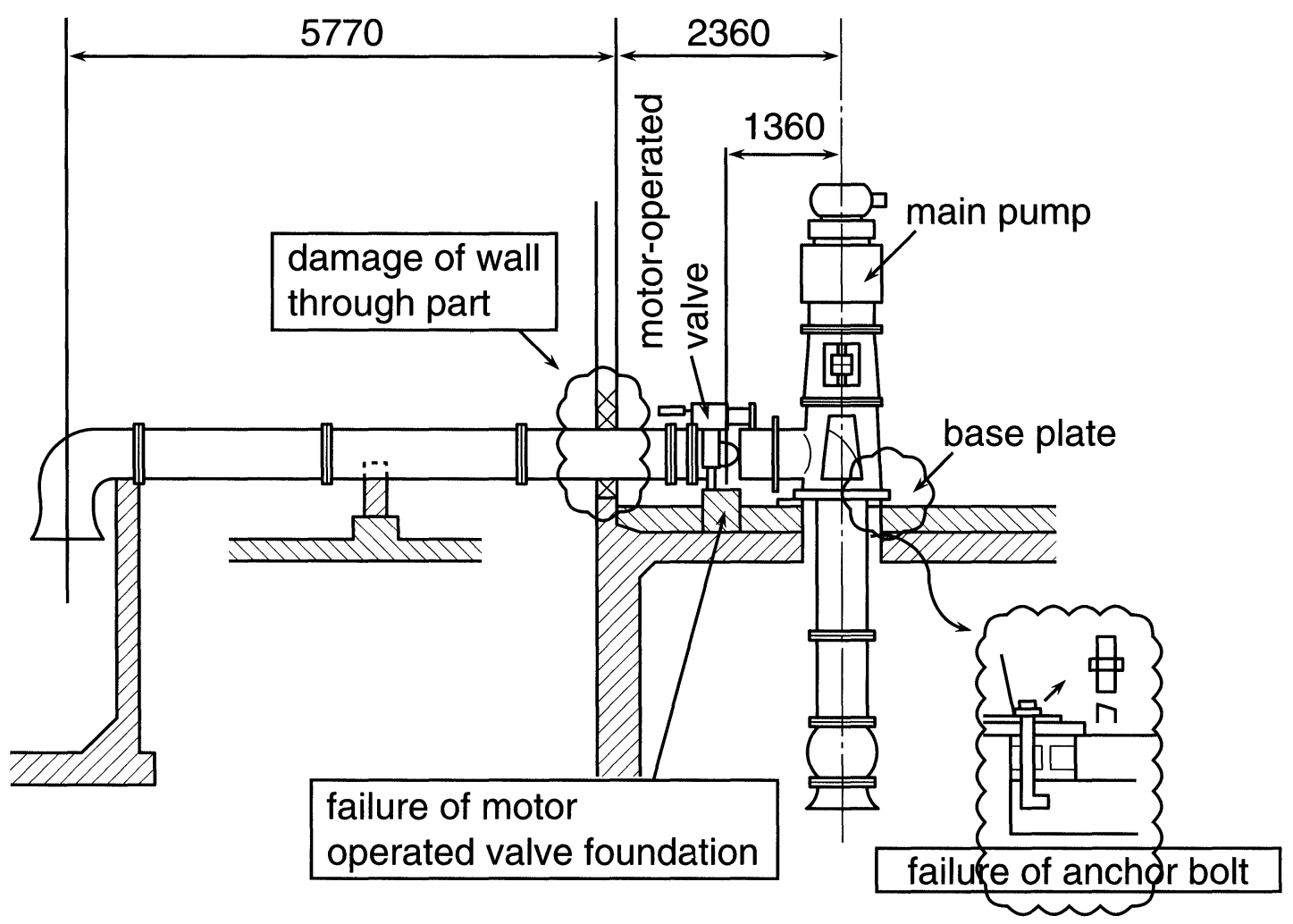

FIGURE 8 Anchor bolt failure. Since a large load from the piping due to unequal sinking of foundation and inertia force was applied to the pump, shear fracture of all the pump anchor bolts $(\mathrm{W} 1 \times 4)$ occurred. 


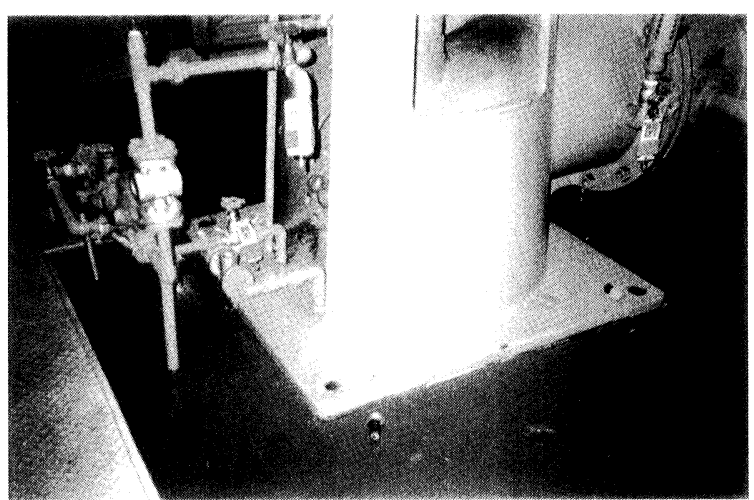

PHOTO 1 Anchor bolt failure. Shear fracture of all the pump anchor bolts $(\mathrm{W} 1 \times 4)$ occurred due to excessive piping load.

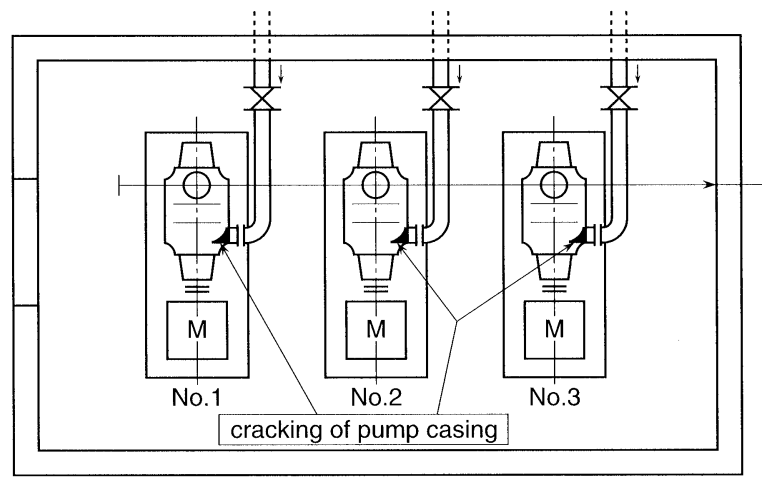

FIGURE 9 Suction casing cracking. The inlet pipe and pump casing were pulled apart by excessive piping external force due to unequal sinking of the building, and failure of the pump casing occurred.

measure for this, the complete pumps were replaced with new ones.

(g) Inclination of pump The horizontal shaft gear type oil pump (discharge opening diameter $25 \mathrm{~mm}$ ) was inclined with the pump foundation, as shown in Photo 2, due to unequal sinking of the foundation. This pump was installed outside the building containing the main pumps. It is assumed that the ground sank a lot because the foundation was dug and filled up again and hence the ground was soft. As an emergency measure for this, test operation of the pump was performed after visual inspection. It was confirmed that oil leakage, vibration, noise, etc. were normal. The

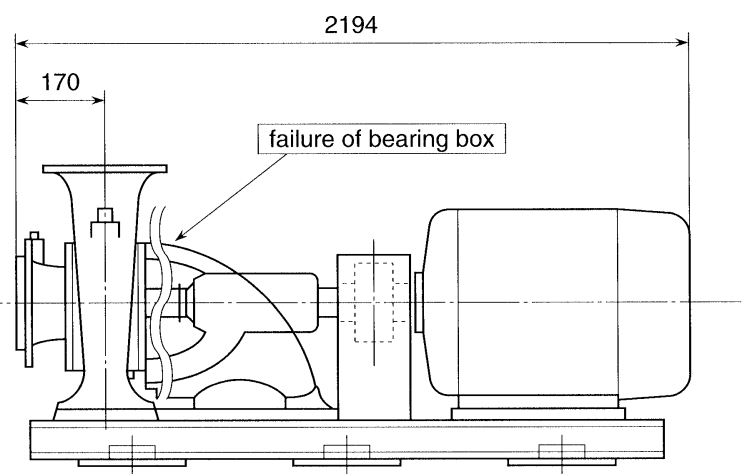

FIGURE 10 Bearing box failure. Several pumps sustained damage such as complete failure in the bracket part of the pump bearing box due to excessive load from the piping and foundation.

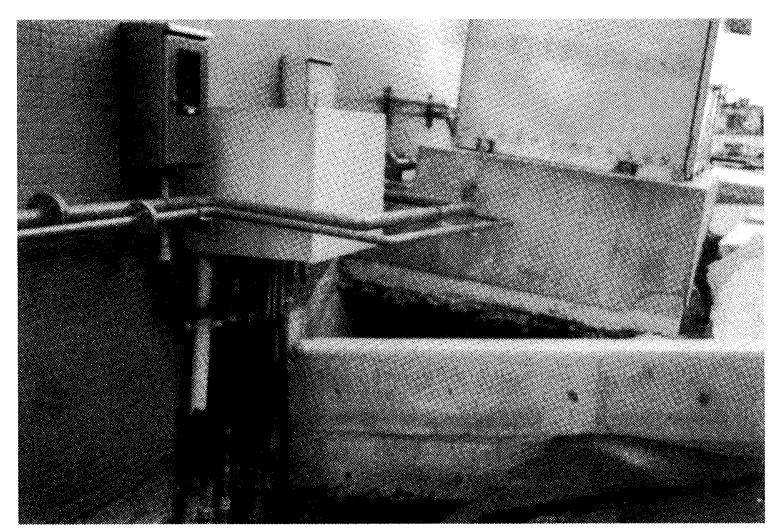

PHOTO 2 Inclination of pump. Oil pump inclined with pump foundation due to unequal sinking of foundation.

foundation was later reconstructed and the pump was restored completely. The future topic of interest is the integration of the foundation with the main pump building adjacent to the oil pump.

(h) Leakage from outlet flange Leakage from the outlet flanges is a typical damage of the piping from the viewpoint of securing pumping function. Figure 11 shows the outlet piping line of a horizontal submerged shaft pump (discharge opening diameter $600 \mathrm{~mm}$ ). Cracks were found in the foundation concrete due to excessive piping load caused by relative displacement of the foundations of the suction water tank and the discharge water tank. Slippage occurred on the piping flange 


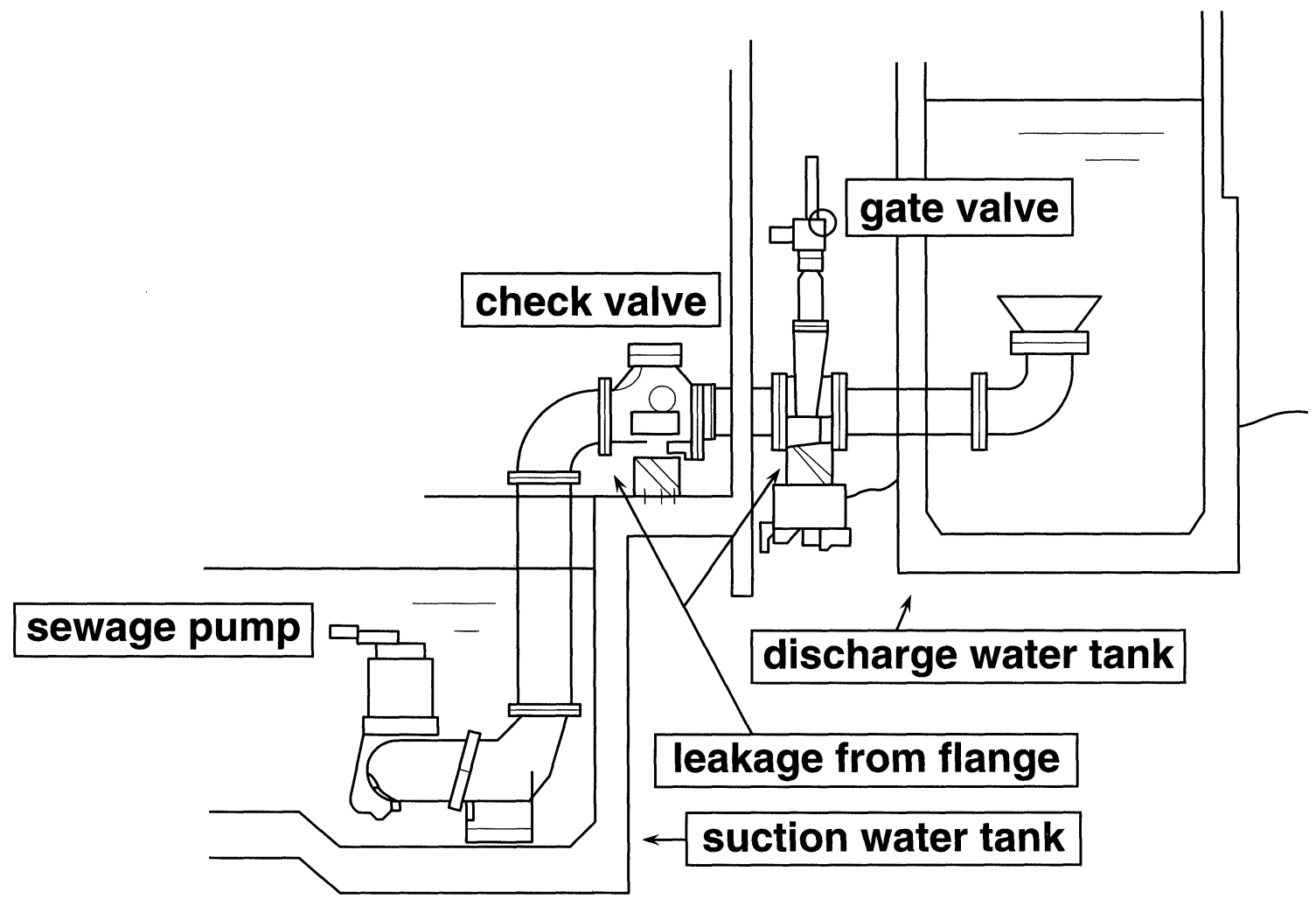

FIGURE 11 Leakage from outlet flange. Slippage occurred on the piping flange surfaces, caused by relative displacement of the foundations of the suction water tank and the discharge water tank, resulting in leakage.

surfaces, resulting in leakage. As correction measures for this, a flexible expansion joint was inserted and reassembled. To prevent recurrence, it is important to consider installation of a flexible expansion joint in the location where the foundation strength changes rapidly, and integration of the foundations.

\subsection{Relation between Damage and Seismic Intensity}

For Kobe City, the distribution of the seismic intensity (maximum acceleration) has been estimated by Sato (1996). Table II and Fig. 12 show the relationship between damage ( 15 cases in total) in Kobe and seismic intensity. No explicit correlation between damage and seismic intensity was apparent. However, seven cases of damage which account for approximately $50 \%$ cases were found in relatively low seismic acceleration below $500 \mathrm{Gal}$ from viewpoint of magnitude of seismic intensity. Most cases occurred in the reclaimed land along the coast. It might be surmised that unequal sinking of the ground occurred, even for relatively low seismic intensity, due to soft ground caused by reclamation, and thus large cases of damage were induced.

\section{EARTHQUAKE RESISTANT DESIGN OF PUMPS}

From the viewpoint of improvement of equipment, Fig. 13 shows the future theme of countermeasures for preventing recurrence of pump structure damage described so far. In order to prevent damage of the pump, it can be seen that comprehensive 
Bold line shows 600gal. Other lines show intervals of $100 \mathrm{gal}$.

observation point is marked $O$.

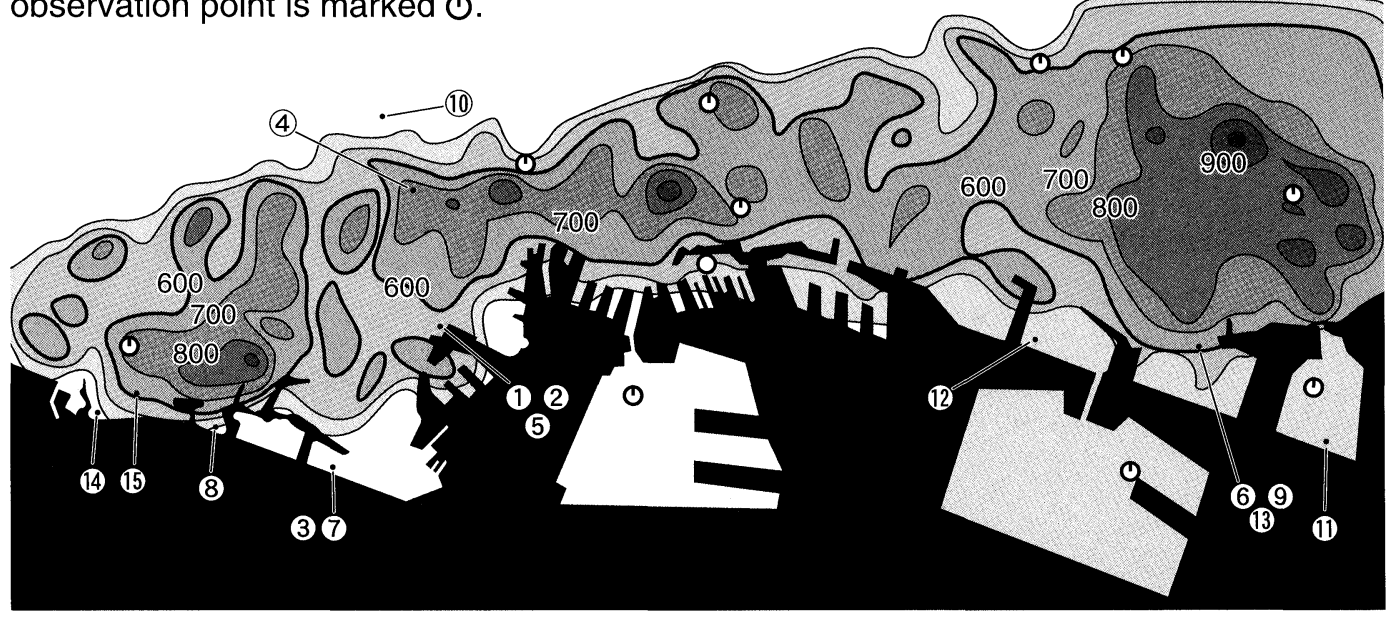

(1)-(15) show the locations of damaged pump facilities.

(refer to Table II for correspondence with damage)

FIGURE 12 Estimated maximum acceleration and the location of pump damage. Seven cases of damage which account for approximately $50 \%$ cases were found in relatively low seismic acceleration below 500 Gal. Most cases occurred in the reclaimed land along the coast.

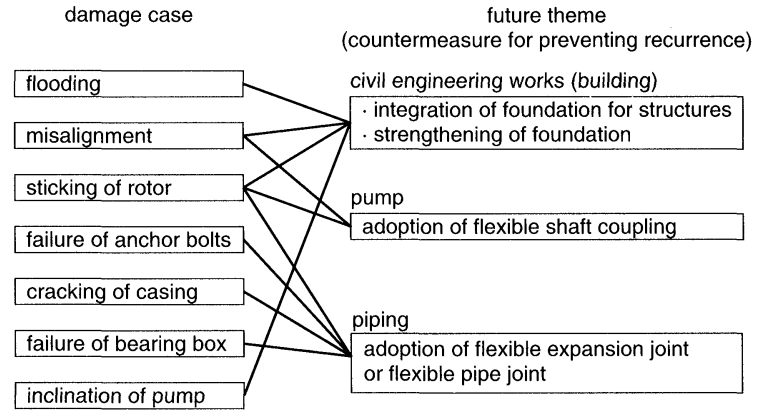

FIGURE 13 Relationship between damage to pump and countermeasures to prevent it. In order to prevent damage of the pump, comprehensive study not only on the pump itself but also on civil engineering works and piping is required.

study not only on the pump itself but also on civil engineering works (building and foundation) and piping is required. This study should be performed from the design stage.

From the above examination of the damage cases, it is found that damage of the pump occurred mainly from secondary causes: most cases were caused by excessive external force applied by piping system due to unequal sinking of the building foundation (ground) or caused by collapse of buildings, etc. Namely, the direct damage to the pump itself from the vibration energy of earthquake was not identified.

As the reason for the above, the earthquake resistant strength of the pump is discussed below. As an example, the calculation of the design thickness of the casing is generally based on the maximum working pressure in the system. Cast iron is used for most of pump casings. For such cases, the thickness of the actual casing is determined by the minimum thickness required for castability. This means that the actual strength is more than that required for the maximum working pressure. As a result, it allows for sufficient strength against external forces (earthquake forces, etc.). This applies also to the support structure which is designed to match the casing. However, the earthquake resistant strength of the pump should be properly studied in order to verify the above.

In Japan, pumps for thermal and nuclear power plants have so far been evaluated based on the earthquake resistant standard of power plants, 
JEAG 4601 (1987) and JEAG 3605 (1991) published by Japan Electric Association. On the other hand, sewage and drainage of storm sewage in which many cases of damage were found have no law for aseismic standard and these have been designed based on manufacturers' experience or standards. However, as for the drainage of storm sewage specified by the Ministry of Construction, the evaluation items, such as anchor bolts of pump and reduction gear, etc., have been added and revised by Association for Pump System Engineering (1996) referring to the case of the Hanshin Earthquake.

In order to prevent damage in future earthquakes, a study of earthquake resistant design is significantly important. As for the pump itself, it should be confirmed that anchor bolts are not damaged by tension or shear caused by overturning moment or horizontal seismic force, and careful consideration should be given to shaft misalignment. On the other hand it is desirable that the system is designed so that the external force from piping, etc., does not exert excessive force on the pump which is a rotating machine. From a practical point of view, support design absorbing seismic load from the piping side, use of flexibility of the piping itself (piping layout), insertion of flexible expansion joint (pipe joint) into the piping adjacent to the pump and wall fixed with the piping, etc. are considered to be useful for avoiding damage from earthquakes. It should be required that foundation and building supporting these equipment are constructed firmly, and important equipment are installed on the same foundation whenever possible.

\section{CONCLUSION}

As a result of the examination of damage to the pump facilities, it was found that types of damage to the pump itself were mainly caused by excessive external force from the piping system due to unequal sinking of the building foundation (ground) or rupture of the building. It is believed that such types of damage have close relation to whether or not the relevant facilities have been planned on the basis of the clear earthquake resistant design standard. No significant correlation between damage and seismic intensity was found. On the other hand, many cases of damage were found in the reclaimed area of the coast where most cases were caused by unequal sinking of the ground due to soft ground and this occurred even for relatively low seismic intensity.

To minimize damage of existing and new pump facilities in earthquakes and to secure pump function, the earthquake resistant design of the pump itself should be properly studied based on the specified aseismic standard. Furthermore, the evaluation of earthquake resistance of complete pumping facilities such as the civil engineering works (groundbuilding) design for preventing damage of building and unequal sinking of foundation (ground), and the piping design for eliminating excessive external force applied to the pump should also be required.

\section{Acknowledgements}

Professors Y. Tsujimoto of Osaka University and H. Kanki of Kobe University are acknowledged for their valuable discussions and support. The present paper was made possible by useful material and valuable support of the following association, persons and corporations. The author would like to express sincere thanks to them: Association for Pump System Engineering, Akira Manabe (Hitachi Ltd.), Hideki Kanno (Ebara Corporation), Yasuo Handa (Torishima Pump Mfg. Co., Ltd.), Yoshitomi Katsube (Awamura Manufacturing Co., Ltd.), Shoichi Yonemura (Kubota Corporation), Takaaki Suzuki (Nikkiso Co., Ltd.), Tatsumi Kimura (DMW Corporation) and Kotaro Karita (Teikoku Electric Mfg. Co., Ltd.).

\section{References}

Anton, W.F. (1981) Seismic Design of Pumping Plants, Journal of the Technical Councils of ASCE, 107(1).

JEAG 3605 (1991) (in Japanese) Technical Guidelines for Aseismic Design of Thermal Power Plants, Electrotechnical Standards Survey Committee, Japan Electric Association. 
JEAG 4601 (1987) Technical Guidelines for Aseismic Design of Neuclear Power Plants, Electrotechnical Standards Survey Committee, Japan Electric Association.

Lund, L.V. (1994) Lifelines Performance in the Landers and Big Bear (California) Earthquakes of 28 June 1992, Bulletin of the Seismological Society of America, 84(3), 562-572.

Sato, T. (1996) (in Japanese) Estimation of the Maximum Ground Motion in the Area of Seismic Intensity 7, Proceed- ings of the Japan Geotechnial Society (Earth and Foundation), Vol. 44, No. 2, Ser. no. 457, p. 35.

Technical Standard and Design Guideline for Storage and Drainage Pump System (Draft) (1996) (in Japanese), Association for Pump System Engineering. 


\section{ait \\ ENERGY MATERIALS}

M A N E Y publishing

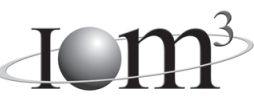

\section{Materials Science \& Engineering for Energy Systems}

Maney Publishing on behalf of the Institute of Materials, Minerals and Mining

The Institute of Materials, Minerals \& Mining

Economic and environmental factors are creating ever greater pressures for the efficient generation, transmission and use of energy. Materials developments are crucial to progress in all these areas: to innovation in design; to extending lifetime and maintenance intervals; and to successful operation in more demanding environments. Drawing together the broad community with interests in these areas, Energy Materials addresses materials needs in future energy generation, transmission, utilisation, conservation and storage. The journal covers thermal generation and gas turbines; renewable power (wind, wave, tidal, hydro, solar and geothermal); fuel cells (low and high temperature); materials issues relevant to biomass and biotechnology; nuclear power generation (fission and fusion); hydrogen generation and storage in the context of the 'hydrogen economy'; and the transmission and storage of the energy produced.

As well as publishing high-quality peer-reviewed research, Energy Materials promotes discussion of issues common to all sectors, through commissioned reviews and commentaries. The journal includes coverage of energy economics and policy, and broader social issues, since the political and legislative context influence research and investment decisions.

\section{CALL FOR PAPERS}

Contributions to the journal should be submitted online at http://ema.edmgr.com

To view the Notes for Contributors please visit: www.maney.co.uk/journals/notes/ema

Upon publication in 2006, this journal will be available via the Ingenta Connect journals service. To view free sample content online visit: www.ingentaconnect.com/content/maney

For further information please contact:

Maney Publishing UK

Tel: +44 (0)113 2497481 Fax: +44 (0)1132486983 Email: subscriptions@maney.co.uk

or

Maney Publishing North America

Tel (toll free): 8662975154 Fax: 6173546875 Email: maney@maneyusa.com

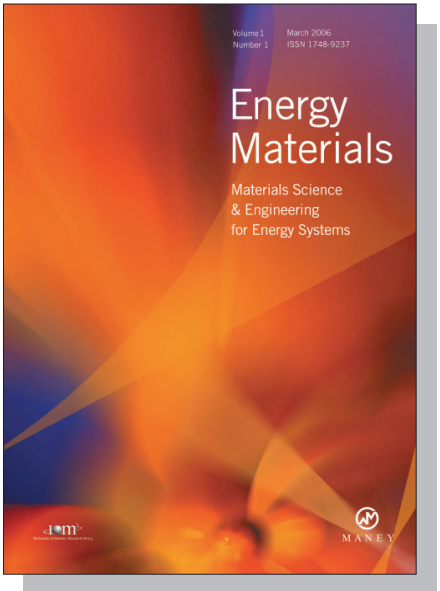

EDITORS

Dr Fujio Abe

NIMS, Japan

Dr John Hald, IPL-MPT, Technical University of Denmark, Denmark

Dr R Viswanathan, EPRI, USA

\section{SUBSCRIPTION INFORMATION}

Volume 1 (2006), 4 issues per year

Print ISSN: 1748-9237 Online ISSN: 1748-9245

Individual rate: $£ 76.00 / U S \$ 141.00$

Institutional rate: $£ 235.00 /$ US $\$ 435.00$

Online-only institutional rate: $£ 199.00 / U S \$ 367.00$

For special $\mathrm{IOM}^{3}$ member rates please email

subscriptions@maney.co.uk

\section{For further information or to subscribe online please visit www.maney.co.uk}



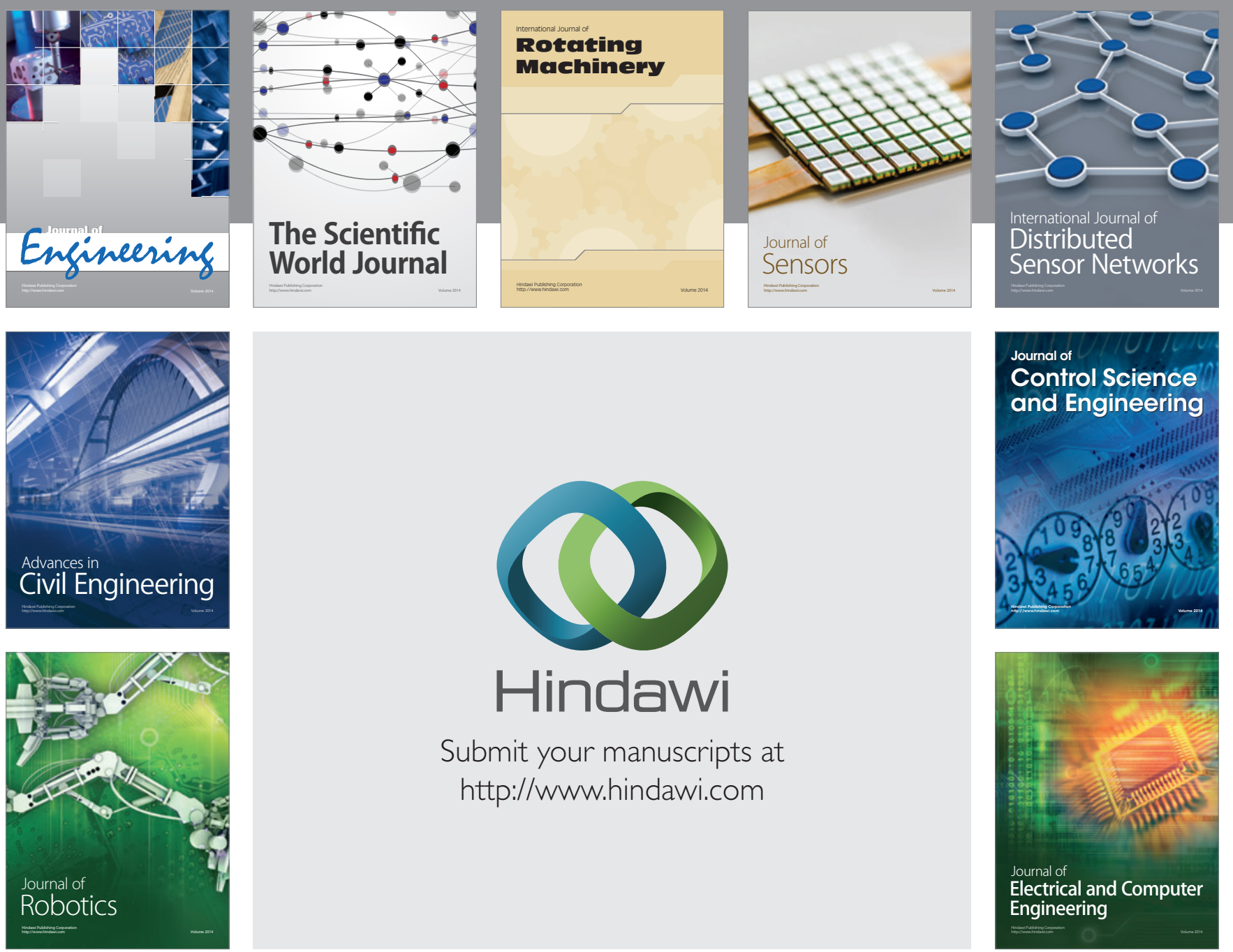

Submit your manuscripts at

http://www.hindawi.com
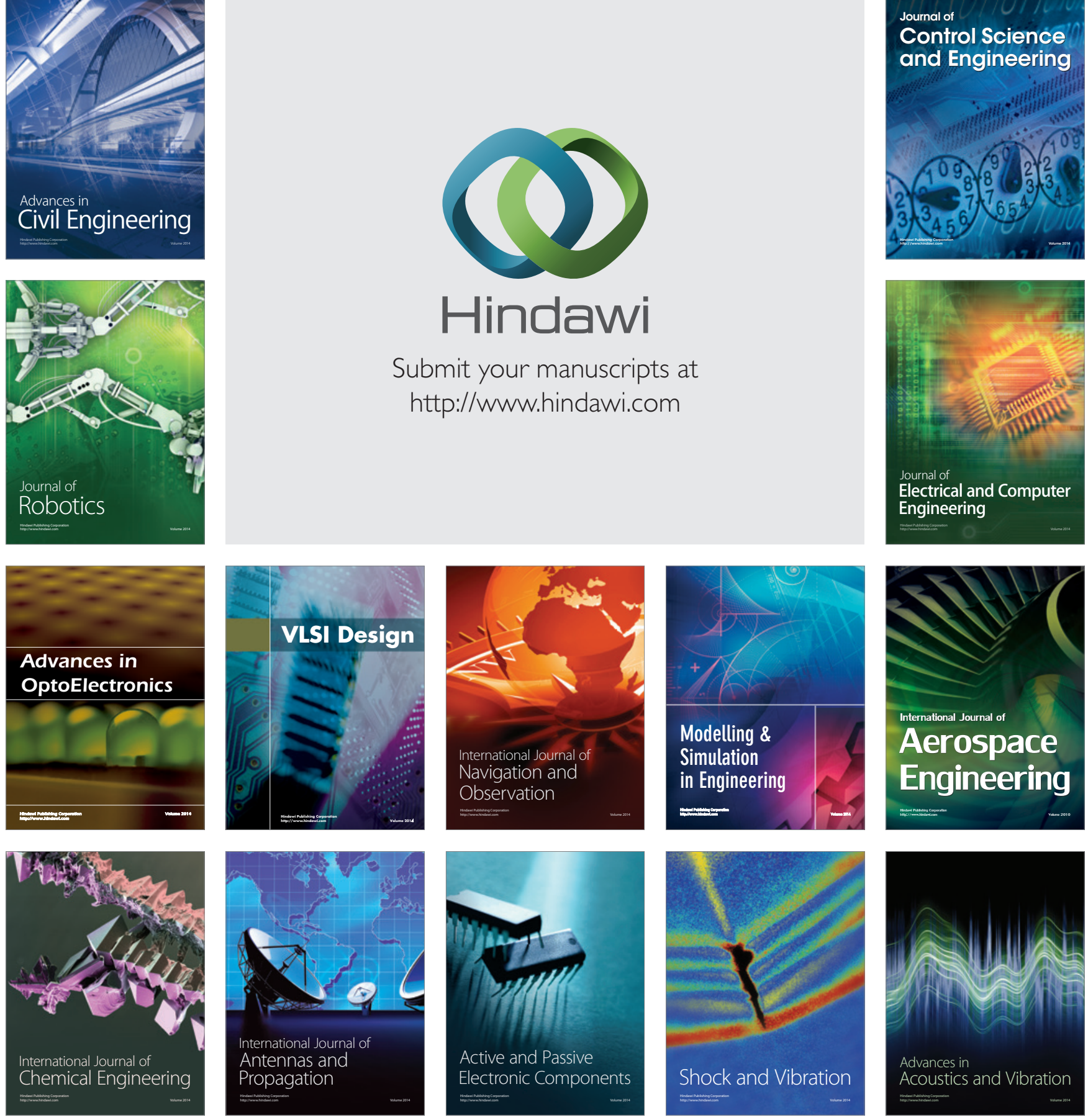